\title{
Common Data Element
}

National Cancer Institute

\section{Source}

National Cancer Institute. Common Data Element. NCI Thesaurus. Code C19984.

Data terms or concepts that have been determined to be identical between projects or contexts. 